\title{
A Linguagem Movimento na Educação de Bebês para a Formação de Professores
}

\author{
Marynelma Camargo Garanhani' \\ Lorena de Fátima Nadolny" \\ 'Universidade Federal do Paraná (UFPR), Curitiba/PR - Brasil \\ "Secretaria Municipal da Educação de Curitiba (SME), Curitiba/PR - Brasil
}

RESUMO - A Linguagem Movimento na Educação de Bebês para a Formação de Professores. Este estudo aborda uma proposta de educação para bebês, ancorada nos pressupostos de Wallon, para discutir estratégias formativas que mobilizam a reflexão de professores sobre saberes da linguagem movimento na Educação Infantil. Para isto, utilizamos estratégias desenvolvidas com professoras de berçários dos Centros Municipais de Educação Infantil de Curitiba (Paraná), em parceria com o projeto de formação de professores Educamovimento: saberes e práticas na Educação Infantil da UFPR (2008-2013). O projeto nos levou a concluir que a formação continuada na Educação Infantil necessita promover a reflexão de práticas educativas que superem dificuldades pedagógicas, planejamento de situações educativas em consonância com as características dos bebês e de suas possibilidades de movimentação, a organização do cotidiano pedagógico e suas práticas de movimento.

Palavras-chave: Educação de Bebês. Formação de Professores. Corpo e Movimento.

ABSTRACT - The Language Movement in Babies' Education for Teachers' Development. This study addresses an educational proposal for babies, anchored on Wallon's assumptions, to discuss educational strategies that mobilize teachers' reflections on movement language knowledge in early childhood education. For this, we used strategies developed with nursery teachers of Municipal Centers of Early Childhood Education in Curitiba Paraná, in partnership with the teacher development project 'Educamovement': knowledge and practices in Early Childhood Education of Paraná Federal University (2008-2013). The project led us to the conclusion that continuing education in early childhood education needs to promote reflection of educational practices that overcome pedagogical difficulties, planning educational situations in line with the characteristics of babies and their movement possibilities, the organization of everyday teaching and their practices of movement.

Keywords: Babies' Education. Teachers' Education. Body and Movement.

Educação \& Realidade, Porto Alegre, v. 40, n. 4, p. 1005-1026, out./dez. 2015.1005 http://dx.doi.org/10.1590/2175-623651737 


\section{Introdução}

Este estudo apresenta uma proposta de educação para bebês, que se ancora na teoria de Wallon. A escolha dessa teoria justifica-se pela concepção de desenvolvimento humano e de educação que este autor apresenta. E sua utilização, na formação continuada destinada às professoras que atuam nos berçários dos Centros Municipais de Educação Infantil (CMEIs) da Rede Municipal de Ensino (RME) de Curitiba (Paraná), realizada em parceria com o Projeto EDUCAMOVIMENTO: saberes e práticas da Educação Infantil da Universidade Federal do Paraná (UFPR). Assim, apresentamos no estudo estratégias formativas que mobilizam a reflexão sobre os saberes da linguagem movimento na educação de bebês, desenvolvidas neste projeto de formação, assim como considerações e conclusões sobre o estudo.

\section{O Desenvolvimento e a Educação de Bebês: o olhar walloniano}

Wallon (1995) concebe o desenvolvimento humano como uma integração entre o organismo e o meio. Para ele, o processo de desenvolvimento ocorre de forma descontínua e não-linear, ou seja, o desenvolvimento não ocorre pela adição de formas progressivamente complexas, mas por reorganizações de elementos presentes desde o seu início. O processo de desenvolvimento ocorre também na integração entre os diferentes conjuntos ou domínios funcionais': a afetividade, a cognição, o movimento e a pessoa que integra todos os outros. Wallon, também, esclarece-nos que " $[. .$.$] as necessidades da descrição obrigam a tratar se-$ paradamente alguns grandes conjuntos funcionais, o que não deixa de ser um artifício, sobretudo de início, quando as actividades estão ainda pouco diferenciadas" (Wallon, 1995, p. 131).

Assim, uma proposta de educação para criança muito pequena ${ }^{2}$, que tem como foco a movimentação do seu corpo, não necessariamente caracteriza uma concepção de desenvolvimento infantil fragmentada, mas um artifício para aprofundar um dos domínios, priorizado para a discussão: o movimento. Essa proposta, ao abordar o desenvolvimento infantil à luz da psicogenética walloniana, assume, então, a necessidade de compreender a criança no seu meio, integrada pelos domínios da afetividade, da cognição e do movimento. Com o foco no domínio movimento, a proposta de educação assume uma compreensão de desenvolvimento em uma "[...] perspectiva de inacabamento, de movimento, de ruptura, de transformações, que necessita ser constantemente superada para possibilitar a própria evolução humana" (Bastos; Dér, 2000, p. 48).

Para Wallon (1995), o desenvolvimento humano é regido por três leis reguladoras: a alternância funcional, a predominância funcional e a integração funcional. A primeira lei - alternância funcional - indica duas direções opostas que se alternam ao longo do desenvolvimento:

1006 Educação \& Realidade, Porto Alegre, v. 40, n. 4, p. 1005-1026, out./dez. 2015. 
uma centrípeta, cujo movimento predominante é para dentro, para o conhecimento de si. Outra centrífuga, cujo movimento predominante é para fora, para o conhecimento do mundo exterior. A segunda - predominância funcional - é a lei em que ocorre a alternância na predominância dos domínios (afetividade, cognição e movimento) a cada fase do desenvolvimento humano.

A função motora predomina nos primeiros meses de vida da criança, enquanto as funções afetiva e cognitiva se alternam ao longo de todo o desenvolvimento, ora visando à formação do eu (predominância afetiva), ora visando ao conhecimento do mundo exterior (predominância cognitiva) (Dourado; Prandini, 2002, p. 25).

A terceira lei é a chamada integração funcional e diz respeito "[...] às novas possibilidades que não se suprimem ou se sobrepõem às conquistas dos estágios anteriores, mas, pelo contrário, integram-se a elas no estágio subsequente" (Dourado; Prandini, 2002, p. 25).

Assim, a concepção de desenvolvimento de Wallon (1995) caracteriza-se por uma visão de conjunto, em que os domínios da pessoa (afetividade, cognição e movimento) alternam-se em relação à predominância de um sobre o outro em uma integração dinâmica e não linear. Wallon (1995) decompõe esse desenvolvimento em cinco estágios ou etapas:

1. Estágio impulsivo-emocional (0 a 1 ano).

2. Estágio sensório-motor e projetivo (1 a 3 anos).

3. Estágio personalista ( 3 a 6 anos).

4. Estágio categorial (6 a 11 anos).

5. Estágio da puberdade e adolescência (a partir dos 11 anos).

Em cada estágio ocorrem formas de atividades específicas.

Os estágios só adquirem sentido dentro dessa sucessão temporal, uma vez que cada um deles é gestado, preparado pelas atividades do estágio anterior e desenvolve atividades que prepararão a emergência do próximo. Então, será possível perceber quais os comportamentos predominantes em cada um deles. As situações às quais a criança reage são exatamente as que correspondem aos recursos de que dispõe (Mahoney, 2000, p. 12).

Por ser a faixa etária de 1 a 3 anos a idade delimitada para a apresentação de uma proposta de educação, os estágios impulsivo-emocional (0 a 1 ano) e sensório-motor e projetivo (1 a 3 anos) foram o foco de considerações teóricas iniciais deste estudo.

No início do estágio impulsivo-emocional, as reações da criança são essencialmente reflexos, ou seja, automatismos naturais, descargas motoras que são interpretadas pelo meio para atendê-la em suas necessidades.

Educação \& Realidade, Porto Alegre, v. 40, n. 4, p. 1005-1026, out./dez. 2015.1007 
O recém-nascido, no seu comportamento, só tem reacções descontínuas, esporádicas e sem outro resultado que não seja o de liquidar pelas vias então disponíveis quer tensões de origem orgânica, quer as suscitadas por excitações exteriores. As gesticulações não podem ter para ele nenhuma utilidade prática. Nem sequer conseguiriam modificar-lhe uma posição incómoda ou perigosa. É-lhe indispensável uma assistência a todos os instantes. É um ser cujas reacções têm todas necessidades de ser completadas, compensadas, interpretadas. Incapaz de nada efectuar por si só, é manipulado por outrem, e é nos movimentos de outrem que tomarão forma as suas primeiras atitudes (Wallon, 1979, p. 151).

Conforme o bebê desenvolve-se, os movimentos impulsivos (que se apresentam do nascimento até aproximadamente três meses de idade) vão se transformando em movimentos mais elaborados, e a fase da impulsividade vai dando lugar à fase emocional. O papel do outro é fundamental nesse processo, pois, quando ele - o outro - começa a entender os movimentos desordenados do bebê, ele - o bebê - vai fazendo a diferenciação.

Por um mecanismo análogo ao dos reflexos condicionados organizar-se-á uma associação entre, por exemplo, as convulsões de cólera e a mamada ou o passeio nos braços da mamã.

Mas esta simples associação fisiológica é em breve dobrada por uma outra que a faz passar para o plano da expressão, da compreensão, das relações individuais. O efeito obtido torna cada vez mais nitidamente intencional a manifestação emotiva. Torna-se um meio de resultados mais ou menos seguros. E este é um novo campo que se abre à atenção, à sagacidade nascente da criança (Wallon, 1979, p. 151).

Assim é o corpo em movimento que dá sustentação para o desenvolvimento da afetividade e o desenvolvimento das funções mentais.

O estágio sensório-motor e projetivo ( 1 a 3 anos) é caracterizado por atividades de exploração concreta do espaço físico: agarrar, segurar, apontar, andar etc., auxiliadas pela fala.

Em oposição ao estágio impulsivo-emocional, que é subjetivo, centrípeto, com predomínio do caráter afetivo, a nova etapa de desenvolvimento caracteriza-se pela investigação e exploração da realidade exterior, bem como pela aquisição da aptidão simbólica e pelo início da representação. [...] é preponderantemente intelectual, voltada para um aspecto mais objetivo, centrífugo do desenvolvimento (Costa, 2000, p. 31).

É nesse estágio que o movimento espontâneo do corpo transforma-se, aos poucos, em gestos, ou seja, os movimentos corporais são realizados a partir de uma intenção e revestem-se de significação.

1008 Educação \& Realidade, Porto Alegre, v. 40, n. 4, p. 1005-1026, out./dez. 2015. 
Le Boulch $^{3}$ (1982), à luz da teoria de Wallon, explica que, na estruturação da consciência corporal, a percepção dos elementos do espaço precede em muitos meses a percepção do próprio corpo. Le Boulch (1982) ainda esclarece que o período de estruturação do esquema corporal inicia quando a criança começa a deslocar a sua atenção para o seu próprio corpo e a descobrir as suas próprias características corporais. Assim, a apropriação do eu corporal, que consiste na estruturação da consciência corporal, é condição para a apropriação do eu psíquico (estágio do personalismo), e essa apropriação do eu corporal pode ser dividida em duas grandes etapas, as quais se realizam durante os dois estágios iniciais do desenvolvimento: o impulsivo-emocional ( 0 a 1 ano) e o sensório-motor e projetivo (1 a 3 anos). O estágio impulsivo-emocional realiza o recorte corporal dando à criança condições de diferenciar o seu próprio corpo do mundo exterior. Já o estágio sensório-motor e projetivo realiza a integração do corpo próprio (cinestésico) à sua imagem exteroceptiva (corpo visual).

Ao experimentar, sistematicamente, "[...] a diferença de sensibilidade existente entre as diversas partes do seu corpo e os objetos, a criança distingue o que pertence ao mundo exterior (espaço objetivo) e o que é de seu próprio corpo (espaço subjetivo)" (Pereira, 1992, p. 21). Contudo, para que a apropriação do eu corporal consolide-se, ou seja, que a estruturação da consciência corporal, é preciso que o corpo próprio (cinestésico) seja integrado ao corpo visual (das representações) e isto é possível com o aparecimento da função simbólica que ocorre na idade de 1 a 3 anos (estágio sensório-motor e projetivo).

Para Wallon (1979, p. 54-55),

[...] todo o indivíduo é marcado pela civilização, que re-
gula a sua existência e se impõe à sua actividade. A lin-
guagem que dela recebe é o molde dos seus pensamentos,
é ela que estrutura os seus raciocínios. Os instrumentos
que ela lhe propõe dão forma aos seus movimentos.

Assim, apoiadas nessa perspectiva, apresentamos uma proposta para educação de bebês que entende o movimento do corpo não apenas como uma necessidade físico-motora infantil, mas uma dimensão do desenvolvimento humano que proporciona a compreensão, a expressão e a comunicação de significados presentes no meio histórico-cultural (Garanhani, 2004).

\section{O Corpo Infantil em Movimento: uma linguagem da criança}

Na pequena infância, o corpo em movimento constitui a matriz básica da aprendizagem da criança, pois ela transforma em símbolo aquilo que pode experimentar corporalmente e seu pensamento se constrói, primeiramente, sob a forma de ação (Garanhani, 2004). Assim, a criança necessita agir para compreender e expressar significados presentes no contexto histórico-cultural em que se encontra.

Educação \& Realidade, Porto Alegre, v. 40, n. 4, p. 1005-1026, out./dez. 2015.1009 
Wallon (1979) ressalta que, na pequena infância, o ato mental desenvolve-se no ato motor, ou seja, a criança pensa quando está realizando a ação e isso faz com que o movimento do corpo ganhe um papel de destaque nas fases iniciais do desenvolvimento infantil. Entretanto, como isso ocorre?

Para Wallon (1979, p. 74), "[...] o órgão do movimento sob todas as formas é a musculatura estriada" e esta apresenta duas funções: a função cinética e a função tônica. A função cinética caracteriza-se pelo estiramento e encurtamento das fibras musculares e possibilita o movimento propriamente dito. A função tônica é caracterizada pela variação do nível de tensão da musculatura para a manutenção do equilíbrio corporal e constitui as atitudes, ou seja, as reações posturais. Mesmo em uma atividade cinética (o movimento propriamente dito), a musculatura depende da função tônica e esta é necessária para manter a postura corporal.

[...] a função tónica, que mantém no músculo um certo nível de tensão, variável com as condições fisiológicas próprias do sujeito ou com as dificuldades do acto em vias de execução. É o tônus que permite manter os músculos na forma que lhes deu o movimento, no caso de este vir a interromper-se. Acompanha o movimento para suportar o seu esforço na medida das resistências encontradas, mas pode dissociar-se dele e transformá-lo numa atitude estável, ou seja, em imobilidade (Wallon, 1979, p. 74-75).

Assim, a função tônica regula o equilíbrio corporal, no movimento ou na imobilidade, mas é a expressão de emoções sua principal finalidade. As emoções sempre vêm acompanhadas de uma mímica facial e corporal, traduzidas em atitudes que têm significados específicos conforme a cultura a que pertencem. Portanto, "[...] as atitudes estão relacionadas, por um lado, com a acomodação ou a expectativa e, por outro lado, com a vida afectiva" (Wallon, 1979, p.15). Por serem expressivas, as atitudes possuem um caráter altamente contagioso e mobilizador do meio humano (Galvão, 1995). Todavia, “[...] todo este aparelho funcional está longe de se encontrar em estado operacional desde o nascimento. Os seus componentes aparecerão cada um na sua altura, e permitirão então à criança modificar as suas relações com o meio" (Wallon, 1979, p. 75).

Ao descrever o processo do desenvolvimento infantil, Wallon ressalta que a criança, já no início de seu desenvolvimento, estabelece uma relação de comunicação com o meio, por intermédio da seleção de movimentos do corpo que garantem a sua aproximação do outro e a satisfação de suas necessidades. Portanto, na fase inicial do desenvolvimento infantil, os movimentos do corpo apresentam-se como instrumentos expressivos de bem estar e mal estar (Mahoney, 2000). Conforme o desenvolvimento avança, a relação da criança com o meio facilita a discriminação das formas de comunicar-se, desencadeando ao andar

1010 Educação \& Realidade, Porto Alegre, v. 40, n. 4, p. 1005-1026, out./dez. 2015. 
e à fala um salto qualitativo no desenvolvimento da pequena infância, possibilitando uma maior autonomia e independência na investigação do espaço e dos objetos que nele se encontram.

Os objetos e a organização do espaço constituem, nesse momento, uma oportunidade ou ocasião de movimentação e exploração do corpo e, essa constatação, propicia estudos e discussões pedagógicas sobre o material educativo no processo do desenvolvimento da criança pequena (Garanhani, 2004, p. 24).

Nesse processo, a fala acompanhada do andar possibilita ainda à criança o ingresso no mundo dos símbolos. Wallon (1942) enfatiza que é na idade de 2 a 3 anos que a criança conquista a dimensão simbólica do pensamento e isso lhe dará condições de apropriar-se do conhecimento cultural acumulado, historicamente, pelo meio social.

A capacidade de simbolização inicia-se quando a criança começa a imitar ${ }^{4}$ o que vê ao redor e a expressar o seu pensamento por ideomovimentos - pensamentos apoiados em gestos -, o que lhe possibilita ultrapassar os limites sensório-motores do comportamento.

O gesto é capaz de tornar presente o objeto e substituí-lo, ou seja, pelos gestos a criança simula uma situação de utilização do objeto sem tê-lo, de fato, presente; trata-se de um ato sem o objeto real. [...] Essa atividade que o faz-de-conta se faz presente consiste, portanto, na descoberta e no exercício do desdobramento da realidade, pressupondo o início da representação. [...] O desdobramento da realidade só será possível, no entanto, quando houver a subordinação da atividade sensório-motora à representação. Nesse momento, assiste-se ao início da organização do pensamento; a criança é capaz de dar significação ao símbolo e ao signo, ou seja, encontrar para um objeto sua representação e para a representação um signo (Costa, 2000, p. 35).

Para a criança constituir a imagem e representá-la, é preciso antes conhecer e estabelecer relações corporais com o objeto e/ou a situação que serão representados. Oliveira (1996), quando aborda o desenvolvimento infantil explica-nos:

Ao imitar o outro, as crianças necessitam captar o modelo em suas características básicas, percebendo-o a partir de sua plasticidade perceptivo-postural, conforme se ajustam afetivamente a ele. Com isso decodificam o conjunto de impressões que captam do outro, experimentando diversas possibilidades de ações no meio ao qual estão inseridas e diferenciando os elementos originais que são trazidos para a situação presente (Oliveira, 1996, p. 143).

A capacidade de simbolizar amplia-se quando a criança articula a aquisição da fala à manipulação de diferentes objetos e/ou vivências 
corporais de situações diferenciadas, sendo a linguagem ${ }^{5}$ o instrumento que vai elaborar e organizar a expressividade da criança no mundo dos símbolos. Assim, o corpo como um conjunto de dimensões física, afetiva, histórica e social assume um papel fundamental no processo de constituição da criança muito pequena como sujeito ${ }^{6}$ cultural. Nesse cenário, os movimentos do corpo, tão importantes no desenvolvimento físico-motor infantil, também constituem uma linguagem que se constrói no processo histórico-cultural do meio no qual o bebê se encontra.

\section{O Movimento do Corpo na Educação do Bebê}

As considerações teóricas e reflexões apresentadas levaram-nos a (re)pensar uma concepção de educação que valorizasse a movimentação corporal da criança, não somente como uma necessidade físico-motora do desenvolvimento infantil, mas também como uma capacidade expressiva e intencional. Para isso, a escola da pequena infância, ao propiciar um meio favorável ao desenvolvimento infantil nos seus diversos domínios (a afetividade, a cognição e o movimento), deverá realizar a mediação entre a criança e o conhecimento culturalmente construído e traduzido em diferentes linguagens ${ }^{7}$ : oral, corporal, musical, gráfico-pictórica e plástica (Garanhani, 2004). Ao mesmo tempo, deverá desenvolver na criança habilidades para a expressão e a comunicação.

Todavia, para que estejam presentes na educação da pequena infância o conhecimento e o desenvolvimento de diferentes linguagens, é necessário estar atento ao fazer pedagógico da Educação Infantil que deverá contemplar ações que privilegiem diversas formas de interação e comunicação da criança com o meio e com o seu grupo. Essa condição está diretamente atrelada à formação dos profissionais responsáveis pelas instituições educativas de crianças pequenas.

Em seus estudos sobre a formação profissional para a Educação Infantil, Machado (1998; 1999) ressalta que, no desenvolvimento de competências específicas para o cuidado/educação da criança pequena, devem ser contemplados saberes sob as diferentes formas que ela - a criança - utiliza para a apropriação e a construção de conhecimentos. Destacamos, entre eles, os saberes sobre o movimento do corpo.

Assim, a movimentação corporal da criança na prática pedagógica da Educação Infantil poderá, segundo Garanhani (2004; 2010), ser norteada por três eixos:

- Aprendizagens que envolvam movimentações corporais para o desenvolvimento físico e motor, proporcionando o conhecimento, o domínio e a consciência do corpo, condições necessárias para a autonomia e a identidade corporal infantil.

- Aprendizagens que levem à compreensão dos movimentos do corpo como uma linguagem utilizada na interação com o meio através da socialização.

1012 Educação \& Realidade, Porto Alegre, v. 40, n. 4, p. 1005-1026, out./dez. 2015. 
- Aprendizagens que levem à ampliação do conhecimento de práticas corporais historicamente produzidas na e pela cultura em que a criança se encontra.

Esses eixos deverão apresentar-se integrados ao fazer pedagógico da Educação Infantil, embora na elaboração de atividades possa ocorrer a predominância de um sobre o outro conforme as características e as necessidades de cuidado e de educação presentes em cada idade da criança. É necessário ressaltar que um não exclui o outro, eles se completam conforme as leis reguladoras do desenvolvimento humano de Wallon. A Figura 1 a seguir propõe uma representação gráfica desses eixos nos fazeres pedagógicos da Educação Infantil.

\section{Figura 1 - Organização Pedagógica do Movimento na Educação Infantil}

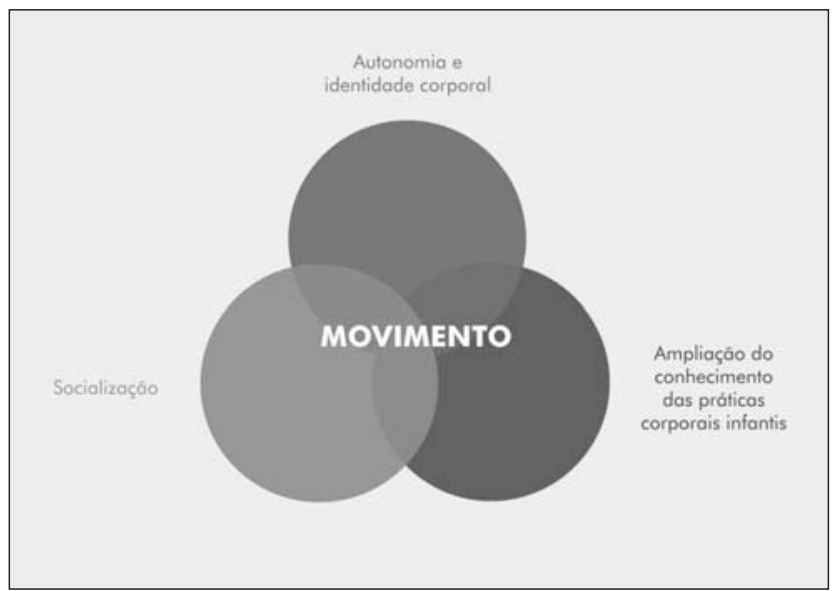

Fonte: Caderno Pedagógico: movimento (Curitiba, 2009a).

Podemos traduzi-la (Figura 1), na educação de bebês, da seguinte maneira: na busca da autonomia de movimentação do seu corpo, a criança constrói sua identidade corporal. No entanto, esse processo só ocorre na relação com o outro, que se encontra em um determinado contexto histórico-cultural, ou seja, ocorre na socialização. Nesse cenário, a criança aproxima-se e apropria-se de elementos da cultura que se traduzem em conhecimentos, atitudes, práticas, valores e normas. Ao ingressar em uma instituição educativa, a criança traz consigo conhecimentos sobre sua movimentação corporal, apropriados e construídos nos diferentes espaços e relações em que vive. O fazer pedagógico deverá sistematizar e ampliar esses conhecimentos, não esquecendo as características e as necessidades de cuidado e educação corporais presentes em cada idade (Garanhani, 2004; 2010).

Ao utilizar esses eixos, na educação de bebês, a seleção e a organização de atividades pedagógicas deverá nortear-se por objetivos, como os exemplos do Quadro 1 que segue.

Educação \& Realidade, Porto Alegre, v. 40, n. 4, p. 1005-1026, out./dez. 2015.1013 
ALinguagem Movimento na Educação de Bebês para a Formação de Professores

Quadro 1 - Sugestões de Objetivos a Serem Tratados nos Eixos de Trabalho Educativo da Linguagem Movimento na Educação Infantil

\begin{tabular}{|c|c|c|}
\hline $\begin{array}{c}\text { Eixo de } \\
\text { trabalho }\end{array}$ & Objetivos & Atividades \\
\hline $\begin{array}{l}\text { Autonomia } \\
\text { e identidade } \\
\text { corporal }\end{array}$ & $\begin{array}{l}\text { - Exploração e conhecimento das possibi- } \\
\text { lidades de movimento do próprio corpo } \\
\text { e suas limitações. } \\
\text { - Adaptação corporal progressivamente } \\
\text { autônoma para satisfação das necessi- } \\
\text { dades básicas e das situações cotidianas. } \\
\text { - Observação das diferenças e semelhan- } \\
\text { ças de sua movimentação corporal em } \\
\text { relação aos outros. } \\
\text { - Disponibilidade e coordenação corporal } \\
\text { na execução de diversas formas de mo- } \\
\text { vimentos que envolvam deslocamentos, } \\
\text { equilíbrios e manipulações de diferen- } \\
\text { tes objetos. } \\
\text { - Autoproteção e desenvoltura corporal } \\
\text { em situações de desafios e perigos. }\end{array}$ & \\
\hline Socialização & $\begin{array}{l}\text { - Confiança nas possibilidades de movi- } \\
\text { mentação corporal. } \\
\text { - Esforço para vencer as possibilidades } \\
\text { superáveis. } \\
\text { - Aceitação das diferenças corporais. } \\
\text { - Colaboração e iniciativa com o grupo. } \\
\text { - Expressão e interpretação de sensações, } \\
\text { sentimentos e intenções. } \\
\text { - Diferenciação de posturas e atitudes } \\
\text { corporais. }\end{array}$ & $\begin{array}{c}\text { Jogos e brinca- } \\
\text { deiras, cantigas } \\
\text { e danças, brin- } \\
\text { cadeiras ginás- } \\
\text { ticas. }\end{array}$ \\
\hline $\begin{array}{l}\text { Ampliação e } \\
\text { conhecimento } \\
\text { das práticas } \\
\text { corporais } \\
\text { infantis }\end{array}$ & $\begin{array}{l}\text { - Conhecimento e/ou reconhecimento, } \\
\text { apropriação e apreciação, construção } \\
\text { e (re)organização das diversas práticas } \\
\text { corporais, presentes no meio sociocul- } \\
\text { tural para a sistematização e amplia- } \\
\text { ção do seu conhecimento em relação } \\
\text { às possibilidades e às maneiras de se } \\
\text { movimentar. }\end{array}$ & \\
\hline
\end{tabular}

Fonte: Elaborado pelas autoras com base em Garanhani (2004).

Nesse cenário, o brincar apresenta-se como um princípio pedagógico, pois na pequena infância esse comportamento propicia à criança condições de agir e de compreender os significados presentes em seu cotidiano. Assim, entende-se que é no brincar que a criança adapta a sua condição físico-motora e a do objeto e/ou situação às condições exigidas pela ação e, consequentemente, ela consegue experimentar, explorar e compreender os significados do meio. Portanto, o brincar propicia uma relação com os símbolos que constituem as atividades do seu cotidiano e, consequentemente, oferece à criança condições de apropriar-se de elementos da realidade por meio da compreensão de seus significados.

1014 Educação \& Realidade, Porto Alegre, v. 40, n. 4, p. 1005-1026, out./dez. 2015. 
Ao brincar em atividades que proporcionem a vivência de movimentos corporais amplos e/ou de representação, a criança desenvolve os seus aspectos físico-motores e, mesmo sendo muito pequena, pode ser levada a entender os significados dos movimentos de seu corpo. A criança pode compreender também que os movimentos corporais que envolvem possibilidades de deslocamento (caminhar, correr, saltar, rolar, etc.), de manipulação de objetos (lançar, pegar, tocar, arremessar etc.) e de equilíbrio (girar, balançar, inclinar, agachar etc.) agrupam-se em diversas práticas e estas, na pequena infância, apresentam-se na forma de jogos e de brincadeiras, atividades rítmicas, brincadeiras ginásticas e artísticas.

Assim, ao ingressar em uma instituição educativa, a criança muito pequena traz consigo conhecimentos sobre os seus movimentos corporais, apropriados e construídos nos diferentes espaços e nas relações em que vive. Desse modo, a escola da pequena infância poderá não só sistematizar e ampliar o conhecimento da criança sobre a sua movimentação, como também favorecer o conhecimento, a apropriação, a apreciação e o domínio de uma linguagem: o movimento do corpo.

Frente a essas considerações é necessário, portanto, disponibilizar saberes aos professores por meio de um processo de formação continuada, priorizando temas que oportunizem a organização do trabalho educativo voltado ao corpo da criança em movimento e à reflexão sobre a prática pedagógica que envolve esse tema.

\section{Formação Continuada: um processo permanente de ressignificação da prática docente}

Como já discutido, os saberes ${ }^{8}$ docentes dos profissionais que atuam na Educação Infantil precisam direcionar-se para um trabalho pedagógico que considere e valorize as diferentes linguagens utilizadas pela criança na sua expressão e comunicação com o meio em que está inserida.

Dentre essas linguagens, destacamos o movimento corporal da criança, pois estudos realizados ${ }^{9}$ nos mostram que há limitações no trabalho educativo com essa linguagem nas instituições, limitações essas derivadas muitas vezes pela não presença desse tema nos cursos de formação de professores para a Educação Infantil, ou então pela forma reducionista pela qual é abordado. Esses estudos apontam a não compreensão do movimento como uma linguagem da criança, por meio de ações de controle e padronização da movimentação das mesmas. Apontam também que, quando são desenvolvidas práticas de movimento, há dificuldade no desenvolvimento, sistematização e justificativa para essas práticas.

Assim, a formação continuada, enquanto “[...] atividade que contribui para o repertório de modos de aprendizagem usados atualmente,

Educação \& Realidade, Porto Alegre, v. 40, n. 4, p. 1005-1026, out./dez. 2015.1015 
no sentido de promover o crescimento dos indivíduos e das instituições, realizando-se tanto dentro como fora das mesmas instituições" (Day, 2001, p. 203) desempenha um papel fundamental no processo de construção e de ressignificação dos saberes sobre o movimento do corpo para a atuação docente na Educação Infantil, como espaço coletivo de produção e troca de diferentes saberes por meio de um processo permanente de reflexão sobre a prática docente.

Nesse cenário, há a necessidade de pensarmos como mobilizario essa reflexão, pois além de fatores pessoais, a prática reflexiva precisa de contextos que favoreçam o seu desenvolvimento. Isso porque, apesar de existirem certas atitudes e predisposições pessoais nos professores para a reflexão, há todo um conjunto de destrezas ou habilidades que precisam dominar para concretizar uma prática reflexiva (García, 1995).

Torna-se necessário, portanto, pensar em diferentes estratégias formativas, as quais podem ser consideradas recursos, ou seja, meios utilizados na formação de professores para propiciar a prática reflexiva, a qual pode ser entendida como a ação permanente do professor de refletir e de avaliar criticamente a sua prática no sentido de compreendê-la e modificá-la, com o objetivo de ressignificá-la (Nadolny, 2010).

Assim, as estratégias formativas constituem uma forma de fazer com que os profissionais reflitam sobre a sua prática, tornando-os mais competentes na análise das questões cotidianas para sobre elas agirem (Alarcão, 2003). Nesse sentido, as estratégias podem propiciar uma maior autoconsciência pessoal e profissional, favorecendo o conhecimento, a análise e a avaliação da própria prática docente.

Partindo dessas considerações, apresentamos na sequência uma discussão sobre estratégias formativas utilizadas para a mobilização da reflexão sobre os saberes da linguagem movimento na educação de bebês, as quais foram desenvolvidas com as professoras de berçários dos CMEIs de Curitiba.

\section{Formação Continuada de Professoras ${ }^{11}$ dos Berçários de CMEIs de Curitiba: em foco a linguagem movimento ${ }^{12}$}

Garanhani (2004), no estudo realizado em um CMEI de Curitiba, apresenta que a fala dos profissionais e a prática pedagógica mostraram que há iniciativas para o trabalho pedagógico do movimento do corpo infantil, mas os professores, independentemente de suas formações, relatam dificuldades na sistematização e na justificativa de atividades referentes a esse trabalho. Desse modo, é necessário planejar ações de formação que levem os professores a reconhecer o valor pedagógico do movimento do corpo na educação da criança pequena, reconhecendo- o como uma linguagem presente na pequena infância. Para isso, é necessário formar profissionais conscientes das práticas educativas que desenvolvem e dispostos a refletirem sobre elas, assim como mobiliza-

1016 Educação \& Realidade, Porto Alegre, v. 40, n. 4, p. 1005-1026, out./dez. 2015. 
dos a superarem dificuldades pedagógicas e a criarem ou adaptarem situações educativas em consonância com as características das crianças e do cotidiano pedagógico.

Na Rede Municipal de Ensino (RME) de Curitiba, o processo de formação continuada de professores de Educação Infantil é chamado de formação continuada em serviço e tem como objetivo "[...] aprofundar conceitos, refletir sobre as práticas e fundamentar o trabalho [...]" (Curitiba, 2009b, p. 65). Esse processo é desenvolvido por meio de diferentes modalidades, como cursos presenciais e a distância, palestras e seminários com carga horária e certificação específica, mas é desenvolvido também durante o tempo de permanência ${ }^{13}$ do professor e nas participações em reuniões pedagógicas de sua unidade de trabalho.

Ao propor e executar as referidas ações de formação, a Secretaria Municipal de Educação (SME) apoia-se nas Diretrizes Curriculares para a Educação Municipal de Curitiba (2006, p. 33), as quais orientam que:

\begin{abstract}
Um importante aspecto do processo de formação continuada é respeitar o conhecimento prévio do profissional, destacando o que considera mais significativo, pois a ação que pratica é a que acredita ser a mais acertada. No espaço de formação, esse profissional precisa de elementos para refletir sobre suas práticas e rever suas crenças, no sentido de fundamentar e redimensionar suas ações.
\end{abstract}

Partindo desse entendimento, foi desenvolvido o curso linguagem movimento, o qual foi destinado às professoras que atuam nos berçários únicos ${ }^{14}$ dos CMEIs de Curitiba, em parceria com o projeto de formação Educamovimento: saberes e práticas na Educação Infantil ${ }^{15}$, o qual foi desenvolvido de 2008 a 2013 com a parceria entre a Universidade Federal do Paraná e o Departamento de Educação Infantil da SME de Curitiba. Seu propósito era discutir os saberes da linguagem movimento na formação inicial do futuro professor de Educação Física que iria trabalhar na Educação Infantil e também na formação continuada daquele que já era professor de Educação Física nesta etapa educacional.

Além desse propósito, o referido projeto tinha a intenção de discutir os conhecimentos da área da Educação Física como apoio aos saberes e práticas da linguagem movimento desenvolvidas por profissionais que não possuíam a formação em Educação Física e que atuavam nos CMEIs de Curitiba ${ }^{16}$. Para isso, o Departamento de Educação Infantil, com base nos momentos de estudo e planejamento das ações dos projetos realizados com a UFPR, desenvolveu diferentes ações de formação, dentre elas o curso linguagem movimento, o qual foi selecionado para as discussões e reflexões deste estudo.

Esse curso foi desenvolvido no período de agosto a outubro de 2010. Atendeu um total de 98 professoras e teve a duração de 24 horas, sendo 16 horas presenciais ( 4 encontros de 4 horas cada) e 8 horas a distância.

Educação \& Realidade, Porto Alegre, v. 40, n. 4, p. 1005-1026, out./dez. 2015.1017 
Nos encontros presenciais, foi apresentada a proposta do trabalho educativo da linguagem movimento na Educação Infantil a partir dos eixos autonomia e identidade corporal, socialização e ampliação e conhecimento das práticas corporais infantis (Garanhani, 2004); com a discussão sobre o desenvolvimento do bebê, a importância da linguagem movimento no berçário, práticas de movimento que podem ser desenvolvidas com crianças de 4 meses a 2 anos, a organização de ambientes de aprendizagem para o trabalho educativo com o movimento, objetivos, planejamento e avaliação.

A carga horária a distância correspondeu ao planejamento e ao desenvolvimento de uma prática de movimento na sua turma de atuação (4 horas) e também à elaboração de um diário de formação, em que as professoras registraram suas percepções, suas aprendizagens e suas reflexões sobre o trabalho educativo com a linguagem movimento e o seu processo de formação continuada.

Nessa ação de formação foram utilizadas as seguintes estratégias formativas para mobilizar a reflexão das professoras sobre os saberes do movimento: análise de situações homólogas, análise de bons modelos, redação e análise de casos, narrativas e interlocução teoria e prática.

Segundo Carvalho, Klisys e Augusto (2006), as situações homólogas são práticas escolhidas pelo formador para explicitar os processos dos sujeitos envolvidos em certos atos, bem como levantar discussões a respeito do conhecimento em questão com o objetivo de apoiar o planejamento dos professores. Essa estratégia consiste em não apenas vivenciar atividades, mas refletir sobre elas, analisá-las para buscar entender os processos que ocorrem em situações semelhantes e, consequentemente, significá-las. Partindo dessas considerações, foram propostas às professoras de berçário situações homólogas de jogos e brincadeiras, cantigas, danças e brincadeiras ginásticas para que refletissem sobre os saberes do movimento envolvidos nessas práticas e, posteriormente, analisar quais poderiam ser utilizados no fazer pedagógico com os bebês. Refletir sobre as possibilidades de movimentação que os bebês apresentam nas vivências destas práticas e discutir como analisar o seu desenvolvimento com base nos pressupostos da teoria estudada.

A estratégia análise de bons modelos objetiva não apenas ampliar o repertório dos professores acerca de diferentes práticas que podem ser desenvolvidas com as crianças, mas desenvolver uma reflexão teórica para relacionar os bons modelos às propostas vigentes para que elas possam ser reelaboradas (Carvalho; Klisys; Augusto, 2006). Foram utilizados bons modelos de práticas que foram desenvolvidas nas turmas de berçário por professoras que haviam participado de outros cursos nos anos de 2007 a 2009 e modelos de ambientes de aprendizagem organizados para o trabalho educativo da linguagem movimento. Esses modelos foram apresentados não como exemplos a serem seguidos, mas como possibilidades de análise e estudo.

1018 Educação \& Realidade, Porto Alegre, v. 40, n. 4, p. 1005-1026, out./dez. 2015. 
Como estratégia formativa, o uso de modelos justifica-se porque, em um primeiro momento, as mudanças são apoiadas em esquemas imitativos das práticas que se oferecem. A imitação é mais do que uma simples reprodução,

[...] é um processo dinâmico e criativo, pois quando se imita a ação de alguém, é preciso entender, interpretar o que há nela de essencial para que seja interiorizada de forma própria. Os resultados dessas primeiras assimilações também são discutidos, o que permite a tomada de consciência e a apropriação mais autônoma dos princípios que regem as práticas (Carvalho; Klisys; Augusto, 2006, p. 124).

Desse modo, a imitação de um bom modelo de ensino é mais do que um ato mecânico, exige do professor entender e interpretar o que há naquela situação para interiorizá-la e desenvolvê-la de forma própria. Por meio de bons modelos foi possível mostrar às professoras o trabalho educativo da linguagem movimento com bebês, para que visualizassem a teoria na prática e as possibilidades de executá-la.

A estratégia redação e análise de casos também foi utilizada e consiste em registros de acontecimentos da prática pedagógica que permitem a análise, a discussão e a reflexão sobre as situações descritas pelos professores. Com base em um conhecimento teórico, a análise de casos possibilita “[...] a partilha de pontos de vista sobre uma mesma situação, que poderá ser interpretada de modo diferente por cada um dos intervenientes nesse estudo, uma vez que os conhecimentos teóricos, adquiridos ou construídos, possibilitam essa diversidade" (Alarcão, 1996, p. 108). No último encontro do curso, as professoras apresentaram e analisaram as práticas de movimento que foram planejadas e desenvolvidas nos berçários como parte da carga horária a distância. Nesse momento, elas puderam refletir sobre os objetivos do trabalho, os encaminhamentos metodológicos realizados e as aprendizagens das crianças por meio de suas próprias práticas com os bebês.

As narrativas foram utilizadas como estratégia pelo fato de constituírem uma ferramenta para a reflexão profissional a partilhar com os colegas. Elas permitem ao professor analisar o seu percurso profissional, revelar filosofias e padrões de atuação, registrar aspectos conseguidos e aspectos a melhorar (Alarcão, 2003). Quando escrevemos, organizamos o nosso fazer pedagógico. Portanto, as narrativas, ou seja, escrever sobre o seu fazer pedagógico com os bebês mobilizou as professoras ao exercício da prática reflexiva sobre a linguagem movimento na Educação Infantil e estas narrativas foram registradas em um diário $^{17}$, o qual denominamos diário de formação.

A construção do diário, como parte da carga horária a distância, mobilizou as professoras a refletirem sobre a sua prática docente e seus trechos ilustram o processo de reflexão que elas realizaram.

Os movimentos pareciam ter sentido no outro dia quando cheguei no CMEI. Tudo o que as crianças faziam eu observava de uma maneira dife-

Educação \& Realidade, Porto Alegre, v. 40, n. 4, p. 1005-1026, out./dez. 2015.1019 
ALinguagem Movimento na Educação de Bebês para a Formação de Professores

rente. Quero relatar o dia 16/09/10. Quando fiz a atividade em sala, fiquei impressionada como realmente os objetivos são cumpridos quando você sabe o que precisa ser alcançado. Foi incrível porque eu realmente observei o que eles estavam fazendo (Professora 1).

Estou refletindo sobre o movimento e chego à conclusão de que tenho os movimentos corporais pouco desenvolvidos. Penso que preciso melhorar os meus movimentos para poder melhorar o meu trabalho com as crianças. Será que isso tem a ver com não ter trabalhado os movimentos na infância? (Professora 2).

Quando saí do primeiro encontro percebi que trabalhava movimento sem objetivo algum. Após o curso passei a ter um novo olhar. Hoje, quando planejo as atividades de movimento, tenho o cuidado de colocar as atividades de acordo com as crianças, pois trabalho com berçário único (Professora 3).

Quando eu entrei na rede eu não entendia muito bem como trabalhar o movimento. Eu pensava: como assim? Trabalhar o movimento? A criança já se movimenta o tempo todo! Depois passei a entender um pouco mais e, agora no curso linguagem movimento, vi a importância de se trabalhar com o movimento na Educação Infantil (Professora 4).

Conforme observamos nesses trechos, as narrativas mobilizaram a reflexão sobre a importância do trabalho educativo com a linguagem movimento nos berçários, sobre a necessidade de intencionalidade nesse trabalho e também sobre a relação com seu corpo e o conhecimento das possibilidades de sua movimentação. Segundo Scarpa (1998), na formação continuada de professores, a aprendizagem significativa opõe-se à aprendizagem mecânica ou superficial e ocorre quando os saberes apresentados nos cursos relacionam-se de modo substantivo aos conhecimentos prévios dos professores. Assim, quando há a articulação da teoria com os saberes da prática dos professores e quando lhes são oferecidas oportunidades de experienciar ações, atitudes e modos de organização que podem ser desenvolvidos no trabalho educativo com as crianças, são construídas aprendizagens significativas e mobilizadas reflexões sobre a prática pedagógica.

Desse modo, a estratégia interlocução teoria e prática ${ }^{18}$ pode mobilizar a reflexão, pois possibilita que os saberes teóricos articulem-se aos saberes da prática, ao mesmo tempo ressignificando-os e sendo por eles ressignificados (Pimenta, 2006). Essa estratégia foi utilizada em todos os momentos do curso, desde a apresentação da concepção de linguagem movimento no primeiro encontro até o último encontro, em que as professoras analisaram as práticas de movimento desenvolvidas com os bebês.

\section{Para Concluir: algumas considerações finais}

Quando se ensina o bebê a cantar, a rabiscar e/ou desenhar, a brincar com o seu corpo e acompanhar ritmos, a observar as formas de objetos, a manipular brinquedos, a expressar sentimentos, a apreciar

1020 Educação \& Realidade, Porto Alegre, v. 40, n. 4, p. 1005-1026, out./dez. 2015. 
uma imagem, a diferenciar ruídos, palavras e/ou sons, está se proporcionando a apropriação de ferramentas que permitirão que ele se relacione com o meio de maneira cada vez mais elaborada.

\begin{abstract}
Na educação infantil, não se propõe os mesmos objetivos em todas as linguagens: em algumas, o objetivo será incentivar e otimizar aprendizagens já iniciadas; em outras, poder-se-á iniciar pela primeira vez ou de uma maneira diferente da que a criança já estava acostumada. É, portanto, imprescindível fazer um esforço na creche e na pré-escola para trabalhar tudo o que ajude a criança a dispor de ferramentas que lhe permitam começar a tornar-se um indivíduo da sociedade (Bassedas; Huguet; Solé, 1999, p. 75-76).
\end{abstract}

Para isso, contudo, é necessário que as oportunidades de expressão e de comunicação do bebê possam ser asseguradas em propostas pedagógicas que valorizem as diferentes linguagens. Entre elas se faz presente o movimento do seu corpo.

Entendemos o movimento do corpo como uma linguagem não-verbal (Palomo, 2001), pois o movimento do corpo possibilita ao ser humano relações de comunicação e expressão de suas intenções nas experiências oferecidas pelo meio histórico-cultural em que está inserido. Portanto, o movimento do corpo é uma importante dimensão do desenvolvimento e da cultura humana (Brasil, 1998). E o corpo em movimento constitui, na pequena infância, a matriz básica das aprendizagens infantis (Garanhani, 2008).

Partindo dessas considerações, concluímos que a formação continuada das professoras de berçário precisa ser um meio de torná-las conscientes das práticas educativas que desenvolvem, assim como a reflexão de práticas educativas que superem dificuldades pedagógicas, o planejamento de situações educativas em consonância com as características dos bebês e de suas possibilidades de movimentação, a organização do cotidiano pedagógico e suas práticas de movimento.

Assim, as estratégias formativas podem e devem ser utilizadas como recursos que mobilizam estas profissionais a refletirem criticamente sobre as suas práticas no sentido de avaliá-las, compreendê-las, modificá-las e ressignificá-las, como também, acessar e compreender os saberes do movimento como uma linguagem da criança.

Essas conclusões nos levam ao entendimento de que a formação continuada deverá ser o espaço de divulgação do trabalho, de conhecimento das novas práticas, de reflexão das ações, de interação das experiências, de superação das dificuldades e, consequentemente, de reorganização da atuação docente, principalmente, quando se trata da educação de bebês e suas possibilidades de movimentação. 


\section{Notas}

1 Wallon utiliza outras palavras, além das citadas no texto, para nomear os conjuntos ou domínios funcionais. Como, por exemplo, em sua obra A evolução psicológica da Criança (Lisboa: Edições 70, 1995), ele utiliza as palavras: afetividade, conhecimento, ato motor e pessoa. Porém, este estudo, optou por utilizar as palavras: afetividade, cognição, movimento e pessoa.

2 Nesta proposta faremos uso da expressão criança muito pequena para nos referirmos aos bebês, ou seja, crianças com menos de 3 anos de vida (Vygotsky, 1984, p. 109).

3 Segundo Dantas (1992), Le Boulch, um dos estudiosos da área da Educação Física, baseia-se nos pressupostos teóricos de Wallon devido a sua compreensão do significado psicológico do movimento.

4 A imitação para Wallon “[...] é, ao mesmo tempo, participação e desdobramento do ato, contradição que anuncia o nascimento da representação e revela sua importância para o desenvolvimento psicológico da criança" (Costa, 2000, p. 34). Segundo Galvão (1995, p. 72), “[...] para Wallon, a imitação é uma forma de atividade que revela, de maneira incontestável, as origens motoras do ato mental".

5 Neste estudo, entende-se linguagem como conceitua Palomo (2001, p. 12), "[...] um sistema complexo de significação e de comunicação". A autora complementa a definição ao dizer que "[...] a linguagem pode ser de dois tipos: a) verbal, aquela cujos sinais são as palavras; b) não-verbal, aquela que emprega outros sinais que não as palavras, como as imagens, os sons, os gestos" (Palomo, 2001, p. 11).

6 Neste estudo, a compreensão de sujeito apoia-se nas considerações de Charlot (2000) que diz que o sujeito é um ser humano, social e singular, que se produz e é produzido por meio da educação. Para essa compreensão, é necessário considerar que toda relação de mim comigo mesmo passa pela minha relação com o outro, ou seja, o que é preciso compreender é a forma social de ser singular e a forma singular de ser social.

7 Palomo (2001, p. 13) conclui, curiosamente, em seu estudo, que "[...] o homem de hoje deixou de lado a concepção ingênua de que só o falar poderia ser linguagem e, mais ainda, de que o seu falar (a sua língua) seria melhor do que as outras. Busca ser bilíngüe e até multilíngue. Constrói suas mensagens de maneiras cada vez mais elaboradas, aproveitando todas as possibilidades que o sistema lhe oferece. Não abre mão dos inúmeros meios de expressão não-verbais. Mas, principalmente, se libertou da mais ingênua das concepções e aceitou que vários sistemas significantes podem existir sem se construírem necessariamente com o auxílio da língua ou a partir do seu modelo".

8 Saberes, segundo o conceito de Tardif (2002), englobam, em um sentido mais amplo, os conhecimentos, as competências, as habilidades (ou aptidões) e as atitudes dos docentes.

9 Galvão (1996), Sayão (2002; 2008), Filgueiras (2002), Garanhani (2004; 2005), Richter e Vaz (2005; 2010), Basei (2008) e Costa (2008).

10 "O conceito de mobilização implica a ideia de movimento, mobilizar é pôr em movimento; mobilizar-se é pôr-se em movimento. Para insistir nessa dinâmica é que utilizamos o termo 'mobilização', de preferência ao de 'motivação'. A mobilização implica mobilizar-se ('de dentro'), enquanto que a motivação

1022 Educação \& Realidade, Porto Alegre, v. 40, n. 4, p. 1005-1026, out./dez. 2015. 
enfatiza o fato de que se é motivado por alguém ou por algo ('de fora')" (Charlot, 2000, p. 54-55).

11 Utilizamos o termo professora considerando que a maioria de profissionais que atuam na educação infantil é do sexo feminino, especialmente nas turmas de berçário.

12 A Educação Infantil na Rede Municipal de Educação de Curitiba está presente nos Centros Municipais de Educação Infantil (CMEIs) nos Centros de Educação Infantil (CEIs) Conveniados e em Escolas Municipais, as quais possuem turmas de Pré (4 a 5 anos). Atuam nessas unidades aproximadamente 4 mil profissionais, dentre eles professores, pedagogos e diretores, os quais possuem formações diferenciadas devido às exigências de contratação via concurso público.

13 Permanência é o termo utilizado na RME de Curitiba para referir-se aos momentos de estudos e planejamentos dos professores e que varia de 4 a 8 horas semanais de acordo com a carga horária desses profissionais. Esses momentos de estudo são desenvolvidos pelo pedagogo da unidade, o qual atua como formador "[...] de modo contínuo e planejado, garantindo que as permanências sejam espaços efetivos de reflexão sobre a prática, a avaliação e o replanejamento do trabalho" (Curitiba, 2009b, p. 65).

$14 \mathrm{O}$ termo berçário único é usado na RME de Curitiba para referir-se às turmas de crianças de 4 meses a aproximadamente 2 anos de idade.

15 Consideramos necessário destacar que nós, as autoras desse estudo, fomos as coordenadoras do referido projeto. Todo o processo de desenvolvimento do projeto, bem como suas ações e estratégias formativas, poderão ser conhecidas na leitura do estudo Garanhani; Nadolny (2014).

16 Na RME de Curitiba os professores de Educação Física atuam somente nas turmas de pré das escolas, pois a contratação desses professores via concurso público prevê a atuação nas turmas de Educação Infantil e Ensino Fundamental da escola; e atuam também em alguns CEIs conveniados, os quais têm autonomia na contratação de profissionais. Até o momento, não houve um concurso público voltado à atuação de professores de Educação Física nos CMEIs.

17 Segundo Zabalza (2004, p. 18), os diários são recursos para a reflexão sobre a própria prática, pois “[...] racionaliza-se a vivência ao escrevê-la (o que tinha uma natureza emocional ou afetiva passa a ter, além disso, natureza cognitiva, tornando-se assim mais manejável), reconstrói a experiência, com isso dando a possibilidade de distanciamento e de análise e, no caso de desejá-lo, se facilita a possibilidade de socializar a experiência, compartilhando-a com um assessor pessoal ou com o grupo de trabalho".

18 Ao considerarmos que a teoria tem papel fundamental na prática reflexiva - pois "[...] dota os sujeitos de variados pontos de vista para uma ação contextualizada, oferecendo perspectivas de análise para que os professores compreendam os contextos históricos, sociais, culturais, organizacionais e de si próprios como profissionais" (Pimenta, 2006, p. 24) -, e que não é possível descontextualizá-la da prática docente, definimos uma estratégia de formação chamada Interlocução teoria e prática.

\section{Referências}

ALARCÃO, Isabel (Org.). Formação Reflexiva de Professores: estratégias de supervisão. Porto: Porto, 1996.

Educação \& Realidade, Porto Alegre, v. 40, n. 4, p. 1005-1026, out./dez. 2015.1023 
ALARCÃO, Isabel. Professores Reflexivos em uma Escola Reflexiva. São Paulo: Cortez, 2003.

BASEI, Andréia Paula. A Educação Física na Educação Infantil: a importância do movimentar-se e suas contribuições no desenvolvimento da criança. Revista Iberoamericana de Educación, Madrid, n. 47/3, p. 1-12, out. 2008.

BASSEDAS, Eulália; HUGUET, Teresa; SOLÉ, Isabel. Aprender e Ensinar na Educação Infantil. Porto Alegre: Artes Médicas Sul, 1999.

BASTOS, Alice Beatriz Izique; DÉR, Leila Christina Simões. Estágio do Personalismo. In: MAHONEY, Abigail Alvarenga; ALMEIDA, Laurinda Ramalho. Henri Wallon: psicologia e educação. São Paulo: Loyola, 2000. P. 39-49.

BRASIL. Referenciais Curriculares Nacionais para a Educação Infantil. Brasília: MEC/SEF, 1998.

CARVALHO, Silvia Pereira de; KLISYS, Adriana; AUGUSTO, Silvana (Org.). Bem-Vindo, Mundo: criança, cultura e formação de educadores. São Paulo: Peirópolis, 2006.

CHARLOT, Bernard. Da Relação com o Saber: elementos para uma teoria. Porto Alegre: Artes Médicas Sul, 2000.

COSTA, Lúcia Helena F. Mendonça. Estágio Sensório-Motor e Projetivo. In: MAHONEY, Abigail Alvarenga; ALMEIDA, Laurinda Ramalho. Henri Wallon: psicologia e educação. São Paulo: Loyola, 2000. P. 31-38.

COSTA, Ana Christina Brandão. Estátua! Se mexer...: Não vale! O conhecimento do movimento corporal na formação do educador infantil. In: CONGRESSO INTERNACIONAL EM ESTUDOS DA CRIANCCA: INFÂNCIAS POSSÍVEIS, MUNDOS REAIS, 1, 2008, Braga. Anais... Braga: 2008.

CURITIBA. Diretrizes Curriculares para a Educação Municipal de Curitiba. Curitiba: SME, 2006.

CURITIBA. Caderno Pedagógico: movimento. Curitiba: SME, 2009a.

CURITIBA. Parâmetros e Indicadores de Qualidade para os Centros Municipais de Educação Infantil. Curitiba: SME, 2009b.

DANTAS, Heloysa. Do Ato Motor ao Ato Mental: a gênese da inteligência segundo Wallon. In: TAILLE, Yves de La; OLIVEIRA, Marta Kohl de; DANTAS, Heloysa. Piaget, Vygotsky, Wallon: teorias psicogenéticas em discussão. São Paulo: Summus, 1992. P. 35-44.

DAY, Christopher. Desenvolvimento Profissional de Professores: os desafios da aprendizagem permanente. Porto: Porto, 2001.

DOURADO, Ione Collado; PRANDINI, Regina Célia Almeida Rego. Henri Wallon: psicologia e educação. Augusto Guzzo Revista Acadêmica, São Paulo, n. 5, p. 23-31, nov. 2002.

FILGUEIRAS, Isabel Porto. A Criança e o Movimento: questões para pensar a prática pedagógica na educação infantil e no ensino fundamental. Revista Avisa Lá, São Paulo, n. 11, p. 1-6, jul. 2002.

GALVÃO, Izabel. Henri Wallon: uma concepção dialética do desenvolvimento infantil. Petrópolis: Vozes, 1995.

GARANHANI, Marynelma Camargo. Concepções e Práticas Pedagógicas de Educadoras da Pequena Infância: os saberes sobre o movimento corporal da criança. 2004. 145 f. Tese (Doutorado em Psicologia da Educação) - Pontifícia Universidade Católica de São Paulo, São Paulo, 2004.

1024 Educação \& Realidade, Porto Alegre, v. 40, n. 4, p. 1005-1026, out./dez. 2015. 
GARANHANI, Marynelma Camargo. O Movimento da Criança no Contexto da Educação Infantil: reflexões com base nos estudos de Wallon. Contrapontos, Itajaí, v. 5, n. 1, p. 81-93, jan./abr. 2005.

GARANHANI, Marynelma Camargo. A Educação Física na Educação Infantil: uma proposta em construção. In: ANDRADE FILHO, Nelson Figueiredo; SCHNEIDER, Omar (Org.). Educação Física para Educação Infantil: conhecimento e especificidade. São Cristovão: UFES, 2008. P. 123-142.

GARANHANI, Marynelma Camargo. Educação Física. In: PARANÁ. Secretaria de Estado da Educação. Ensino Fundamental de Nove Anos: orientações pedagógicas para os anos iniciais. Curitiba, 2010. P. 69-81.

GARANHANI, Marynelma Camargo; NADOLNY, Lorena de Fatima. Educamovimento: saberes e práticas na Educação Infantil. Relatório técnico, 2008-2013. Secretaria Municipal da Educação de Curitiba - Departamento de Educação Infantil. Curitiba, 2014.

GARCÍA, Carlos Marcelo. A Formação de Professores: novas perspectivas baseadas na investigação sobre o pensamento do professor. In: NÓVOA, Antonio. Os Professores e a sua Formação. Lisboa: Nova Enciclopédia, 1995. P. 51-76.

LE BOULCH, Jean. O Desenvolvimento Psicomotor: do nascimento até 6 anos. Porto Alegre: Artes Médicas, 1982.

MACHADO, Maria Lucia de. Formação Profissional para a Educação Infantil: subsídios para idealização e implementação de projetos. 1998. 274 f. Tese (Doutorado em Educação) - Pontifícia Universidade Católica de São Paulo, São Paulo, 1998.

MACHADO, Maria Lucia de. Criança Pequena, Educação Infantil e Formação dos Profissionais. Perspectiva, Florianópolis, UFSC, v. 1, p. 85-95, jul./dez. 1999.

MAHONEY, Abigail Alvarenga. Introdução. In: MAHONEY, Abigail Alvarenga; ALMEIDA, Laurinda Ramalho. Henri Wallon: psicologia e educação. São Paulo: Loyola, 2000. P. 9-18.

NADOLNY, Lorena de Fatima. Estratégias de Formação Continuada para Professores de Educação Infantil: em foco os saberes do movimento. 2010. $101 \mathrm{f}$. Dissertação (Mestrado em Educação) - Universidade Federal do Paraná, Curitiba, 2010.

OLIVEIRA, Zilma Ramos de. A Brincadeira e o Desenvolvimento Infantil: implicações para a educação em creches e pré-escolas. Motrivivência, Florianópolis, v. 7, n. 9, p. 136-145, dez. 1996.

PALOMO, Sandra Maria Silva. Linguagem e Linguagens. Eccos Revista Científica, São Paulo, v. 3, n. 2, p. 9-15, dez. 2001.

PEREIRA, Maria Izabel Galvão. O Espaço do Movimento: investigação no cotidiano de uma pré-escola à luz da teoria de Henri Wallon. 1992. 115 f. Dissertação (Mestrado em Filosofia e História da Educação) - Universidade de São Paulo, São Paulo, 1992.

PIMENTA, Selma Garrido. Professor Reflexivo: construindo uma crítica. In: PIMENTA, Selma Garrido; GHEDIN, Evandro (Org.). Professor Reflexivo no Brasil: gênese e crítica de um conceito. São Paulo: Cortez, 2006. P. 17-54.

RICHTER, Ana Cristina; VAZ, Alexandre Fernandez. Corpos, saberes e infância: um inventário para estudos sobre a educação do corpo em ambientes educacionais de 0 a 6 anos. Revista Brasileira de Ciências do Esporte, Porto Alegre, v. 26, n. 3, p. 79-93, maio 2005.

Educação \& Realidade, Porto Alegre, v. 40, n. 4, p. 1005-1026, out./dez. 2015.1025 
RICHTER, Ana Cristina; VAZ, Alexandre Fernandez. Educação Física, educação do corpo e pequena infância: interfaces e contradições na rotina de uma creche. Movimento, Porto Alegre, v. 16, n. 1, p. 53-70, jan./mar. 2010.

SAYÃO, Deborah Thomé. Cabeças e Corpos, Adultos e Crianças: cadê o movimento e quem separou tudo isso? Revista Eletrônica de Educação, São Carlos, v. 2, n. 2, p. 92-105, nov. 2008.

SAYÃO, Deborah Thomé. Corpo e Movimento: notas para problematizar algumas questões relacionadas à Educação Infantil e à Educação Física. Revista Brasileira de Ciências do Esporte, Porto Alegre, v. 23, n. 2, p. 55-67, jan. 2002.

SCARPA, Regina. "Era assim, agora não...”: uma proposta de formação de professores leigos. São Paulo: Casa do Psicólogo, 1998.

TARDIF, Maurice. Saberes Docentes e Formação Profissional. Rio de Janeiro: Vozes, 2002.

VYGOTSKY, Lev Semenovich. A Formação Social da Mente. São Paulo: Martins Fontes, 1984.

WALLON, Henri. Do Acto ao Pensamento: ensaio de psicologia comparada. Lisboa: Moraes Editores, 1942.

WALLON, Henri. Psicologia e Educação da Criança. Lisboa: Veiga, 1979.

WALLON, Henri. A Evolução Psicológica da Criança. Lisboa: Edições 70, 1995.

ZABALZA, Miguel Angel. Diários de Aula: um instrumento de pesquisa e desenvolvimento profissional. Porto Alegre: Artmed, 2004.

Marynelma Camargo Garanhani é doutora em Educação e Professora do Programa de Pós-graduação em Educação da Universidade Federal do Paraná (UFPR). Coordenadora do EDUCAMOVIMENTO: grupo de pesquisa e estudos em educação da criança, vinculado ao Núcleo de Estudos e Pesquisas em Infância e Educação Infantil (NEPIE-UFPR).

E-mail: marynelma@ufpr.br

Lorena de Fátima Nadolny é mestre em Educação e Doutoranda do Programa de Pós-Graduação em Educação da UFPR. Pesquisadora do EDUCAMOVIMENTO: grupo de pesquisa e estudos em educação da criança. Atua no Departamento de Educação Infantil da Secretaria Municipal da Educação de Curitiba - PR.

E-mail: lorenaedf@gmail.com 